Guaju - Revista Brasileira de Desenvolvimento Territorial Sustentável

Programa de Pós-Graduação em Desenvolvimento Territorial Sustentável (PPGDTS/UFPR)

Publicação semestral. v. 5, n. 1, jan./jun. 2019

\title{
Expediente
}

Dossiê Temático: GÊNERO, TERRITÓRIO E DECOLONIALIDADE

Organização do Dossiê:

Natália Tavares de Azevedo

Katya Regina Isaguire-Torres

Carolina dos Anjos

\section{Equipe editorial:}

Marisete T. Hoffmann-Horochovski

Aline de Oliveira Gonçalves

Simone Ferreira Naves Angelin

Etienne Cesar Rosa Vaccarelli

Natália Tavares de Azevedo

\section{Fotografia da capa:}

Natália Tavares de Azevedo

\section{Diagramação da capa:}

William Leal 